\title{
A theoretical model for predicting the spatial distribution of gas hy- drate dissociation under the combination of depressurization and heating without the discontinuous interface assumption
}

\author{
Lele Liu ${ }^{\mathrm{a}, \mathrm{b}, \mathrm{c}, *}$, Xiaobing $\mathrm{Lu}^{\mathrm{c}}$, Xuhui Zhang ${ }^{\mathrm{c}}$ \\ ${ }^{a}$ Key Laboratory of Gas Hydrate, Ministry of Land and Resources, Qingdao 266071, China \\ ${ }^{\mathrm{b}}$ Qingdao Institute of Marine Geology, China Geological Survey, Qingdao 266071, China \\ ' Institute of Mechanics, Chinese Academy of Sciences, Beijing 100190, China
}

\section{A R T I C L E I N F O}

\section{Article history:}

Received 28 February 2014

Received in revised form

25 March 2015

Accepted 8 July 2015

Available online 10 July 2015

Keywords:

Gas hydrates

Hydrate dissociation

Spatial distribution

Depressurization

Heating

\begin{abstract}
A B S T R A C T
Spatial distribution of gas hydrate dissociation is essential in analyzing gas recovery and related potential hazards. This work develops a 1D model for predicting the spatial distribution of gas hydrate dissociation under the combination of depressurization and heating in the clay-silty sediments. Without assuming a discontinuous interface and a sudden decrease of pressure, the sediment is divided into a dissociated zone, a dissociating zone, and an undissociated zone. The dissociating zone is further separated into a heating subzone and a non-heating subzone. This work finds that (i) the thicknesses of the dissociating zone and the heating subzone as well as the propagation distance of the hydrate dissociation front are all linear with the square root of time, and the square root of hydrate dissociation time at any location is also linear with the distance between the location and the production well; (ii) the expansion velocity of the dissociating zone is about ninety times faster than that of the heating subzone, and a higher absolute permeability causes a faster expansion velocity of the dissociating zone, but barely affects the expansion velocity of the heating subzone; and (iii) the thickness of the heating subzone is less than $5 \%$ of the thickness of the dissociating zone in the latter stage of the hydrate dissociation process.
\end{abstract}

(c) 2015 Elsevier B.V. All rights reserved.

\section{Introduction}

Gas hydrates $(\mathrm{GH})$ as a source of natural gas exist in the form of ice-like crystals composed of gas and water and are stored in seabed sediments along the continental margin and permafrost regions (Sloan and Koh, 2007). GH dissociation, a phase transition from solid to liquid and gas, may result in dramatical changes of petrophysical, geophysical, and geochemical properties of hydratebearing sediments (HBS) during gas recovery from GH (Waite et al., 2009). Therefore, it is of great importance to have a thorough understanding of the spatial distribution of GH dissociation in sediments, size of the dissociation region and location of the dissociation front in particular (Morikami et al., 2008; Anderson et al., 2008; Ikegami et al., 2008; Primiero et al., 2008). Proposed methods for gas recovery mainly include depressurization, thermal stimulation, inhibitor injection and their combinations (Lee

\footnotetext{
* Corresponding author at: Key Laboratory of Gas Hydrate, Ministry of Land and Resources, Qingdao 266071, China.

E-mail addresses: hydrate_liu@163.com (L. Liu), xblu@imech.ac.cn (X. Lu), zhangxuhui@imech.ac.cn (X. Zhang).
}

and Holder, 2001; Klauda and Sandler, 2005; Sloan and Koh, 2007; Demirbas, 2010), among which the combination of depressurization and heating is the most promising one (Henninges et al., 2005; Moridis et al., 2009; Bai and Li, 2010; Yang et al., 2012).

GH dissociation in HBS is a physical-chemical process including conductive and convective heat transfer, two-phase fluid flow in pores, and intrinsic kinetics of GH dissociation, and its mathematical models normally consist of equations of energy conservation and mass balance along with the intrinsic kinetics of GH dissociation. A number of one-dimensional (1D) analytical models were presented to predict the location of the hydrate dissociation front (HDF) by assuming that GH dissociation happens instantaneously at a discontinuous interface which divides HBS into an undissociated zone and a dissociated zone (Selim and Sloan, 1989; Yousif et al., 1990; Goel et al., 2001; Ji et al., 2001; Tsypkin, 2001; Hong and Pooladi-Darvish, 2003). However, detailed investigations showed that $\mathrm{GH}$ dissociation occurs throughout the undissociated zone because the pressure decrease propagates from the boundary into the undissociated zone (Hong and PooladiDarvish, 2005; Moridis and Kowalsky, 2006). Then Gerami and Pooladi-Darvish (2007) presented a 1D analytical model 


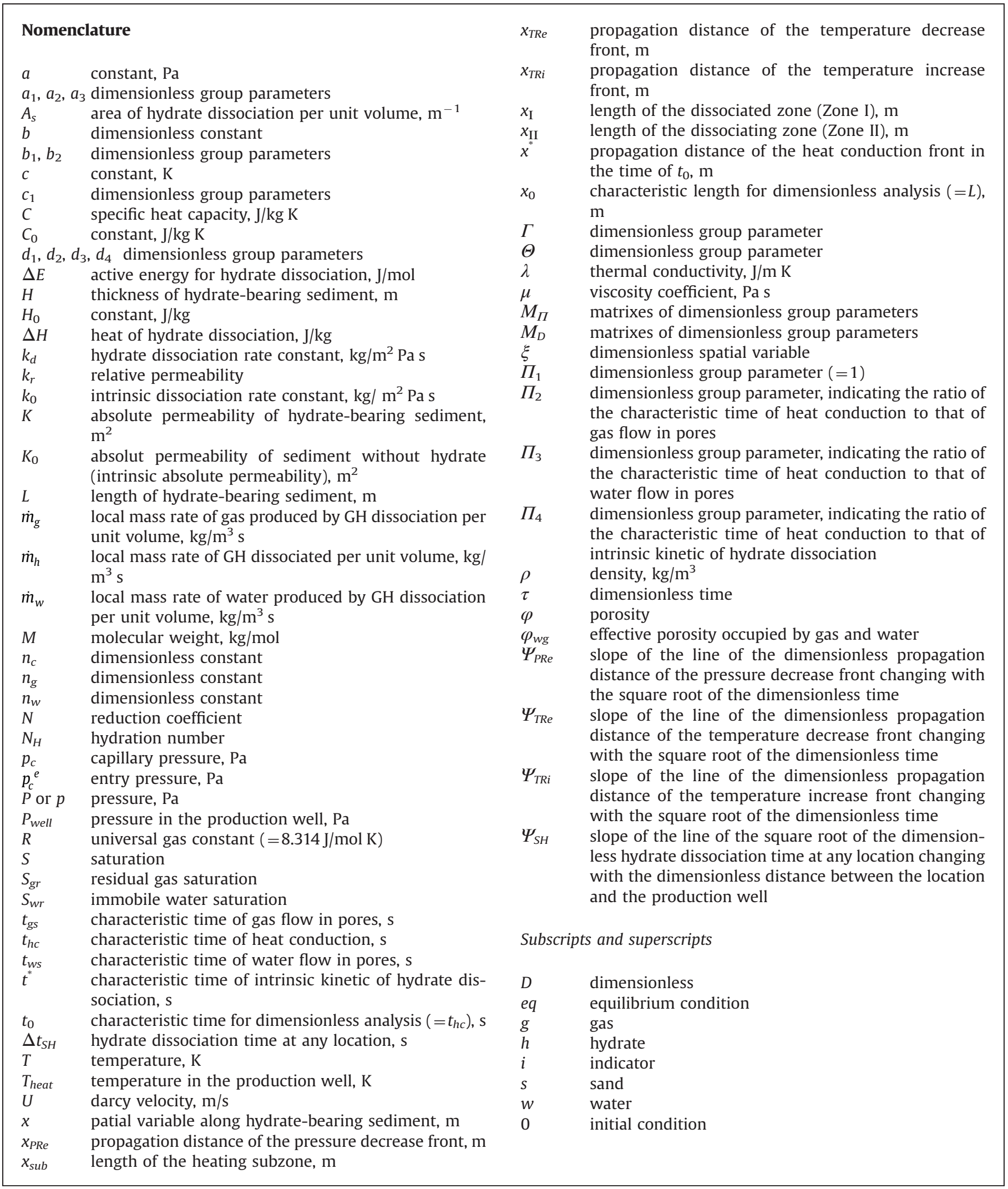

incorporating conductive heat transfer and intrinsic kinetics of $\mathrm{GH}$ dissociation to evaluate the gas production rate. Their model, without the discontinuous interface assumption, assumed that $\mathrm{GH}$ decomposes anywhere inside the undissociated zone when the equilibrium state is destroyed by a sudden decrease of pressure.
But in the clay-silty sediments in Shenhu Area of South China Sea, the pressure decreases only gradually due to the low absolute permeability of HBS (Su et al., 2012).

In order to predict the spatial distribution of GH dissociation under the combination of depressurization and heating in the 
clay-silty sediments, we develop another model without assuming the discontinuous interface and the sudden decrease of pressure.

We start with deriving the mathematical formulae, continue with investigating the spatial distribution of GH dissociation and the effects of dimensionless parameters on it, and conclude with the sensitivity analysis of the key dimensionless parameters.

\section{Description of the problem}

Fig. 1 is a schematic of $\mathrm{GH}$ dissociation by combining depressurization with heating in marine sediments containing clay and soft muds. HBS is partially saturated with $\mathrm{GH}$ and under conditions of uniform pressure $P_{g 0}$ and temperature $T_{0}$ initially, and clapped between an over-layer and a base-layer. Depressurization and heating are operated in a vertical production well passing through HBS (Fig. 1A). The over-layer and the base-layer in the clay-silty sediments are thought to be with low absolute permeability and poor heat conductivity, thus the upper and lower boundaries of HBS are both assumed to be impermeable and adiabatic. HBS is assumed to be thin in height relative to the scale in horizontal direction. Therefore, the cylindrical model can be simplified into a 1D model, with the left end being permeable and isothermal while the right impermeable and adiabatic (Fig.1B).

At time $t=0$, the pressure in the production well is reduced to $P_{\text {well }}$ which is below the equilibrium pressure at $T_{0}$. Meanwhile, the temperature in the production well is increased to $T_{\text {heat }}$ which is above the equilibrium temperature corresponding to $P_{g 0}$. Thus, both the pressure decrease and the temperature increase can lead to $\mathrm{GH}$ dissociation. The pressure and the temperature in the production well remain constant during $\mathrm{GH}$ dissociation.

After a while, HBS can be naturally divided into three zones based on the GH saturation (Fig.1C): a dissociated zone (Zone I), a dissociating zone (Zone II), and an undissociated zone (Zone III). The pressure decrease front (PDeF) expands more quickly than the heat conduction front $(\mathrm{HCoF})$ because the characteristic time of heat conduction is much longer than that of gas flow in pores. Based on HCoF, Zone II can be further separated into two subzones: a heating subzone, and a following non-heating subzone. The temperature in the heating subzone increases as the heat can be directly provided by the production well, while the temperature in the non-heating subzone decreases and approaches the equilibrium temperature at pressure $P_{\text {well }}$ because of the endothermic nature of GH dissociation (Sloan and Koh, 2007; Waite et al., 2009). Therefore, the heat for GH dissociation is provided by the heat conduction from the production well in the heating subzone, and by the sensible heat of HBS in the non-heating subzone.

In this work, the discontinuous interface assumption is NOT adopted. Instead, GH dissociation takes place throughout Zone II once the equilibrium state is destroyed. In addition, the pressure decreases gradually but not suddenly to $P_{\text {well }}$ after depressurization. We take into account all three physical processes: conductive and convective heat transfer, two-phase (gas and water) fluid flow, and intrinsic kinetics of $\mathrm{GH}$ dissociation.

\section{Formulation of the model}

This section presents a 1D mathematical model for $\mathrm{GH}$ dissociation in HBS and develops a dimensionless form of the mathematical model.

Main assumptions are as follows: (i) two-phase (gas and water) flow in HBS obeys Darcy's law; (ii) the methane gas is an ideal gas; (iii) methane can be only in gaseous and solid hydrate states, while water in liquid and solid hydrate states; and (iv) the HBS skeleton is rigid.

\subsection{Controlling equations}

Mass balance equations of gas and water in HBS are

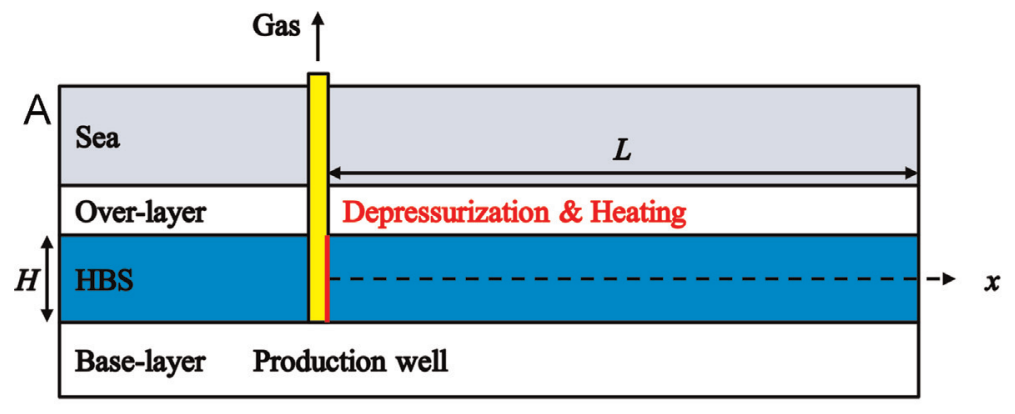

B
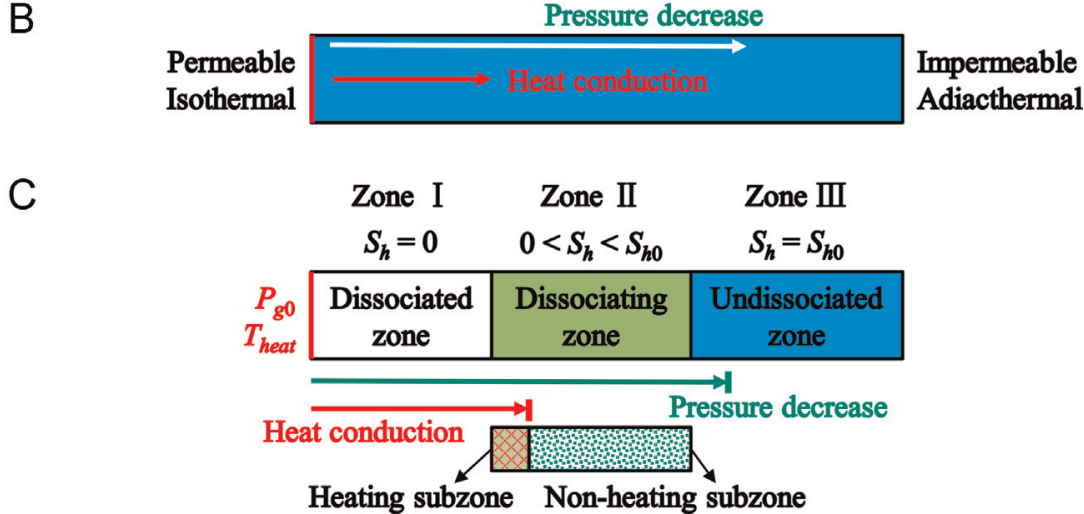

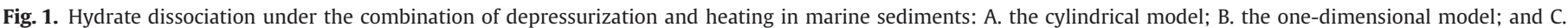
three zones and two subzones in seabed sediments. 
$\frac{\partial}{\partial t}\left(\phi S_{i} \rho_{i}\right)+\frac{\partial}{\partial x}\left(\rho_{i} U_{i}\right)=\dot{m}_{i} \quad i=g, w$

Mass conservation equation of solid $\mathrm{GH}$ is

$\frac{\partial}{\partial t}\left(\phi S_{h} \rho_{h}\right)=\dot{m}_{h}$

Based on the stoichiometry of $\mathrm{GH}$, the generation rates of gas and water are related to dissociation rate of $\mathrm{GH}$ by the following equations:

$\dot{m}_{h}=-\dot{m}_{g} \frac{N_{H} M_{w}+M_{g}}{M_{g}}$

$\dot{m}_{w}=\dot{m}_{g} \frac{N_{H} M_{w}}{M_{g}}$

The rate of GH dissociation per unit volume given by Kim et al. (1987) can be written as

$\dot{m}_{h}=-k_{d}\left(N_{H} M_{w}+M_{g}\right) A_{s}\left(p_{e q}-P_{g}\right)$

where $k_{d}$ is given by Clarke and Bishnoi (2001), which can be expressed as

$k_{d}=k_{0} \exp \left(-\frac{\Delta E}{R T}\right)$

The equilibrium pressure $p_{e q}$ can be expressed as (Sloan and Koh, 2007)

$p_{e q}=a \exp \left(b-\frac{c}{T}\right)$

The interface area between the solid hydrate and fluid phases $A_{s}$ can be calculated using the formula given by Amyx et al. (1960)

$A_{s}=\sqrt{\frac{\left(\phi_{w g}\right)^{3}}{2 K}}$

where the effective porosity $\phi_{w g}$ can be expressed as

$\phi_{w g}=\left(1-S_{h}\right) \phi$

The effective porosity $\phi_{w g}$ increases with GH dissociation, which in turn causes an increase of the absolute permeability of HBS. The University of Tokyo Model (Masuda et al., 1997) is used to describe the relationship between the absolute permeability and the hydrate saturation, which is given by the following formula:

$K=K_{0}\left(1-S_{h}\right)^{N}$

Darcy velocities of gas and water are

$U_{i}=-\frac{k_{r i} K}{\mu_{i}} \frac{\partial P_{i}}{\partial x} \quad i=g, w$

where $\mu$ is assumed to be constant, and $k_{r i}$ can be evaluated by the Corey model (Sun et al., 2005):

$k_{r g}=\left(\frac{\frac{S_{g}}{S_{w}+S_{g}}-S_{g r}}{1-S_{w r}-S_{g r}}\right)^{n_{g}}$

$k_{r w}=\left(\frac{\frac{S_{w}}{S_{w}+S_{g}}-S_{w r}}{1-S_{w r}-S_{g r}}\right)^{n_{w}}$

The equation of state of methane gas is
$\rho_{g}=\frac{P_{g} M_{g}}{R T}$

The relationship between the pressures of gas and water is

$p_{c}=P_{g}-P_{w}$

where $p_{c}$ can be calculated by the following formula (Sun et al., 2005):

$\frac{p_{c}}{p_{c} e^{e}}=\left(\frac{\frac{S_{w}}{S_{w}+S_{g}}-S_{w r}}{1-S_{w r}}\right)^{-n_{c}}$

Saturations of gas, water, and hydrate satisfy the following equation:

$\sum_{i=g, w, h} S_{i}=1$

Energy conservation equation can be expressed as

$\alpha \frac{\partial T}{\partial t}+\beta \frac{\partial T}{\partial x}-\frac{\partial}{\partial x}\left(\lambda \frac{\partial T}{\partial x}\right)=\dot{m}_{h} \Delta H$

$\alpha=(1-\phi) \rho_{s} C_{s}+\sum_{i=g, w, h} \phi S_{i} \rho_{i} C_{i}$

$\beta=\sum_{i=g, w} \rho_{i} U_{i} C_{i}$

$\lambda=(1-\phi) \lambda_{s}+\sum_{i=g, w, h} \phi S_{i} \lambda_{i}$

where $\Delta H$ can be calculated using the formula given by Sloan and Koh (2007)

$\Delta H=H_{0}+C_{0} T$

Initial conditions are shown as follows:

$P_{g}=P_{g 0}$

$T=T_{0} \quad$ at $t=0$

$S_{i}=S_{i 0} \quad i=g, w, h$

and boundary conditions are given by the following equations:

$P_{g}=P_{\text {well }}$

$T=T_{\text {heat }} \quad$ at $x=0$

$\begin{array}{ll}\frac{\partial P_{g}}{\partial x}=0 & \\ \frac{\partial T}{\partial x}=0 & \text { at } x=L\end{array}$

\subsection{Dimensionless forms of the controlling equations}

Dimensionless forms of the Eqs. (1)-(21a, b) can reduce the quantity of variables to find out the key dimensionless parameters (Tan, 2011). Detailed derivation for the dimensionless forms of the Eqs. (1)-(21a, b) is shown in Appendix A.

The dimensionless equations of mass balance for gas and water are

$\Pi_{1} \frac{\partial}{\partial \tau}\left(\frac{P_{D}}{T_{D}} S_{g}\right)-\Pi_{2} \frac{\partial}{\partial \xi}\left(a_{1} \frac{P_{D}}{T_{D}} \frac{\partial P_{D}}{\partial \xi}\right)$

$=\Pi_{4} a_{2}\left(a_{3}-P_{D}\right)$ 
$\Pi_{1} \frac{\partial S_{w}}{\partial \tau}-\Pi_{3} \frac{\partial}{\partial \xi}\left(b_{1} \frac{\partial P_{D}}{\partial \xi}\right)=\Pi_{4} b_{2}\left(a_{3}-P_{D}\right)$

The dimensionless equation of intrinsic kinetics of hydrate dissociation is

$\Pi_{1} \frac{\partial S_{h}}{\partial \tau}=-\Pi_{4} c_{1}\left(a_{3}-P_{D}\right)$

The dimensionless equation of energy conservation is

$\Pi_{1} d_{1} \frac{\partial T_{D}}{\partial \tau}-\Pi_{2} d_{2} \frac{P_{D}}{T_{D}} \frac{\partial P_{D}}{\partial \xi} \frac{\partial T_{D}}{\partial \xi}$

$-\Pi_{3} d_{3} \frac{\partial P_{D}}{\partial \xi} \frac{\partial T_{D}}{\partial \xi}-\frac{\partial}{\partial \xi}\left(\lambda_{D} \frac{\partial T_{D}}{\partial \xi}\right)$

$=\Pi_{4} d_{4}\left(a_{3}-P_{D}\right)\left(T_{D}+\Gamma_{4}\right)$

where dimensionless parameters $\Pi_{1}-\Pi_{4}$ are shown by the following equation:

$\left[\begin{array}{l}\Pi_{1} \\ \Pi_{2} \\ \Pi_{3} \\ \Pi_{4}\end{array}\right]=\left[\begin{array}{c}t_{h c} / t_{0} \\ t_{h c} / t_{g s} \\ t_{h c} / t_{w s} \\ t_{h c} / t^{*}\end{array}\right]$

where $t_{0}$ and $x_{0}$ can be expressed as

$t_{0}=\frac{\Pi_{4}}{\Pi_{1}} t^{*}$

$x_{0}=x^{*} \sqrt{\Pi_{4}}$

The dimensionless forms of initial conditions are given by the following equation:

$P_{D}=P_{g 0} / P_{\text {well }}$

$T_{D}=T_{0} / T_{\text {heat }} \quad$ at $\tau=0$

$S_{i}=S_{i 0} i=g, w, h$

and the dimensionless forms of boundary conditions are as follows:

$P_{D}=1$

$P_{D}=1$
$T_{D}=1$ at $\xi=0$

$\frac{\partial P_{D}}{\partial \xi}=0$
$\frac{\partial T_{D}}{\partial \xi}=0$ at $\xi=\frac{L}{x_{0}}$

\section{Spatial distribution of GH dissociation}

In this section, evolutions of the pressure, the temperature, and the GH saturation which are closely related to the spatial distribution of GH dissociation are discussed first. Then a simple method is presented to determine the spatial distributions of the dissociating zone and the heating subzone.

\subsection{Evolutions of the pressure, the temperature, and the GH saturation}

By using the finite difference method, we develop a numerical simulation code to solve the pressure and the temperature implicitly and the saturations explicitly. The numerical simulation code is verified to be applicable by a laboratory-scale experiment
Table 1

Conditions of the hydrate-bearing sediment under the combination of depressurization and heating (Li et al., 2010; Liu et al., 2012).

\begin{tabular}{ll}
\hline Parameter & Value \\
\hline$S_{h 0}$ & 0.40 \\
$S_{w 0}$ & 0.35 \\
$S_{g 0}$ & 0.25 \\
$T_{0}(\mathrm{~K})$ & 283 \\
$P_{g 0}(\mathrm{MPa})$ & 9.20 \\
$T_{\text {heat }}(\mathrm{K})$ & 373 \\
$P_{\text {well }}(\mathrm{MPa})$ & 4.50 \\
$L(m)$ & 5.00 \\
$\phi$ & 0.25 \\
$K_{0}(\mathrm{mD})$ & 1.00 \\
\hline
\end{tabular}

Table 2

Properties of the hydrate-bearing sediment (Sun et al., 2005; Waite et al., 2009).

\begin{tabular}{lc}
\hline Parameter & Value \\
\hline$C_{s}(\times 103 \mathrm{~J} / \mathrm{kg} / \mathrm{K})$ & 0.89 \\
$C_{h}\left(\times 10^{3} \mathrm{~J} / \mathrm{kg} / \mathrm{K}\right)$ & 2.22 \\
$C_{w}\left(\times 10^{3} \mathrm{~J} / \mathrm{kg} / \mathrm{K}\right)$ & 4.20 \\
$C_{g}\left(\times 10^{3} \mathrm{~J} / \mathrm{kg} / \mathrm{K}\right)$ & 2.18 \\
$\rho_{s}\left(\times 10^{3} \mathrm{~kg} / \mathrm{m}^{3}\right)$ & 2.60 \\
$\rho_{h}\left(\times 10^{3} \mathrm{~kg} / \mathrm{m}^{3}\right)$ & 0.91 \\
$\rho_{w}\left(\times 10^{3} \mathrm{~kg} / \mathrm{m}^{3}\right)$ & 1.00 \\
$\lambda_{s}(\mathrm{~W} / \mathrm{m} / \mathrm{K})$ & 2.9 \\
$\lambda_{h}(\mathrm{~W} / \mathrm{m} / \mathrm{K})$ & 0.46 \\
$\lambda_{w}(\mathrm{~W} / \mathrm{m} / \mathrm{K})$ & 0.56 \\
$\lambda_{g}(\mathrm{~W} / \mathrm{m} / \mathrm{K})$ & 0.07 \\
$\mu_{w}\left(\times 10^{-3} \mathrm{~Pa} \mathrm{~s}\right)$ & 1.00 \\
$\mu_{g}\left(\times 10^{-6} \mathrm{~Pa} \mathrm{~s}\right)$ & 2.45 \\
$N$ & 5.0 \\
$k_{0}\left(\times 10^{4} \mathrm{~mol} / \mathrm{m}^{2} / \mathrm{Pa} / \mathrm{s}\right)$ & 3.60 \\
$\Delta E\left(\times 10^{4} \mathrm{~J}\right)$ & 8.10 \\
$p_{c}{ }^{e}\left(\times 10^{3} \mathrm{~Pa}\right)$ & 4.00 \\
$C_{0}\left(\times 10^{3} \mathrm{~J} / \mathrm{kg} / \mathrm{K}\right)$ & -1.05 \\
$H_{0}\left(\times 10^{6} \mathrm{~J} / \mathrm{kg}\right)$ & 3.53 \\
$S_{g r}$ & 0.02 \\
$S_{w r}$ & 0.20 \\
$n_{g}$ & 2.0 \\
$n_{w}$ & 4.0 \\
$n_{c}$ & 0.65 \\
$a(\mathrm{MPa})$ & 1.15 \\
$b$ & \\
$c\left(\times 10^{3}\right)$ & 9.46 \\
\hline & \\
&
\end{tabular}

of hydrate dissociation by depressurization in a Berea sandstone core carried out by Masuda et al. (1999). More details of the verification will be presented in the discussion chapter. Conditions of HBS under the combination of depressurization and heating are shown in Table 1, and properties of HBS are summarized in Table 2.

The evolution of the pressure after depressurization and heating is shown in Fig. 2. PDeF propagates at $\xi=1$ before $\tau=7.2 \times 10^{-4}$. A turning point occurs in each of the evolution curves, especially in the curve of $\tau=7.2 \times 10^{-4}$. The pressure gradient before the turning point is much bigger than that after the turning point, which is because that the absolute permeability of HBS before the turning point becomes much higher than that after the turning point.

Fig. 3 illustrates the evolution of the temperature after depressurization and heating. Both the temperature decrease front (TDeF) and the temperature increase front (TInF) propagate from the production well into HBS. Moreover, the velocity of TDeF is much faster than that of TInF. The temperature after TDeF decreases and approaches the equilibrium temperature corresponding to $P_{\text {well }}$ because of the endothermic nature of GH dissociation 


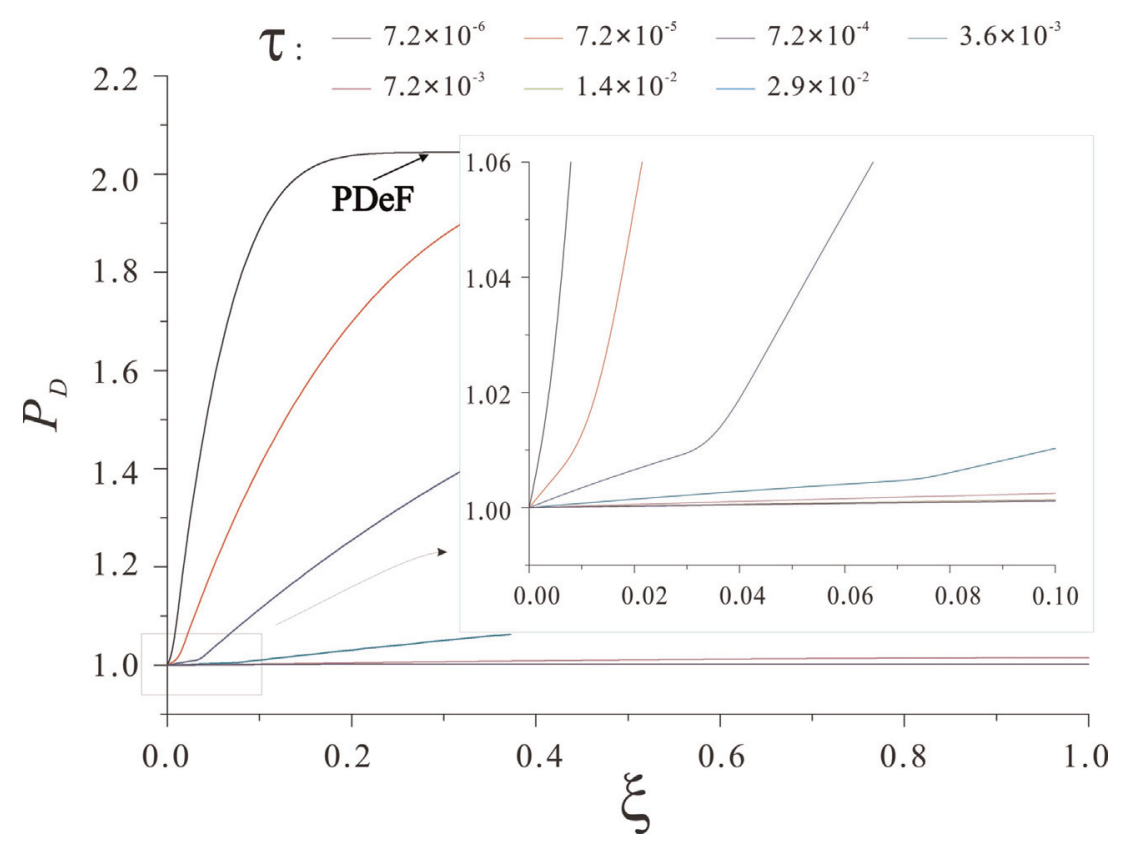

Fig. 2. Evolution of the pressure after depressurization and heating, the right side means "before".

and the temperature after TInF obviously increases because of the energy transferred from the production well. It can be deduced that the location of TInF keeps the same with that of HCoF. A turning point is also observed in each of the evolution curves, and the temperature gradient after the turning point is much larger than that before the turning point.

Fig. 4 shows how the GH saturation changes after depressurization and heating. A turning point occurs around 0.38 in each of the evolution curves. Before the turning point, the hydrate saturation decreases and approaches about 0.38 because the energy for GH dissociation cannot be fully supplied by the sensible heat of HBS, and the hydrate saturation after the turning point decreases to zero in a very short time because the energy for GH dissociation can be completely provided by the production well. It can be deduced that the location of the turning point keeps the same with that of $\mathrm{HCoF}$ all the time after depressurization and heating.

According to PDeF, TDeF, TInF, and HCoF, HBS can be divided into several zones (Fig. 5). In order to estimate the spatial distribution of hydrate dissociation, four time points must be defined at first, which are given as follows:

$\tau_{1}: S_{h}(\xi=0)=0$ and $S_{h}(0<\xi \leq 1) \neq 0$;

$\tau_{2}: \frac{x_{P D e}}{L}=1$, where $x_{P D e}$ is the propagation distance of PDeF;

$\tau_{3}: \frac{x_{T I n}}{L}=1$, where $x_{T I n}$ is the propagation distance of TInF;

$\tau_{4}: \frac{x_{I}}{L}=1$, where $x_{I}$ is the length of Zone I.

Accordingly, the evolution of the dissociating zone (Zone II) evolves in three stages:

Stage I $\left(0 \sim \tau_{1}\right)$ : the length of Zone II $\left(x_{\text {II }}\right)$ is equal to the propagation distance of TDeF $\left(x_{T D e}\right)$;

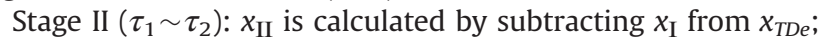

Stage III $\left(\tau_{2} \sim \tau_{4}\right): x_{\text {II }}$ is evaluated by deducting $x_{\text {I }}$ out of $L$.

Similarly, the evolution of the heating subzone also experiences three stages:

Stage I $\left(0 \sim \tau_{1}\right)$ : the length of the heating subzone $\left(x_{s u b}\right)$ is equal

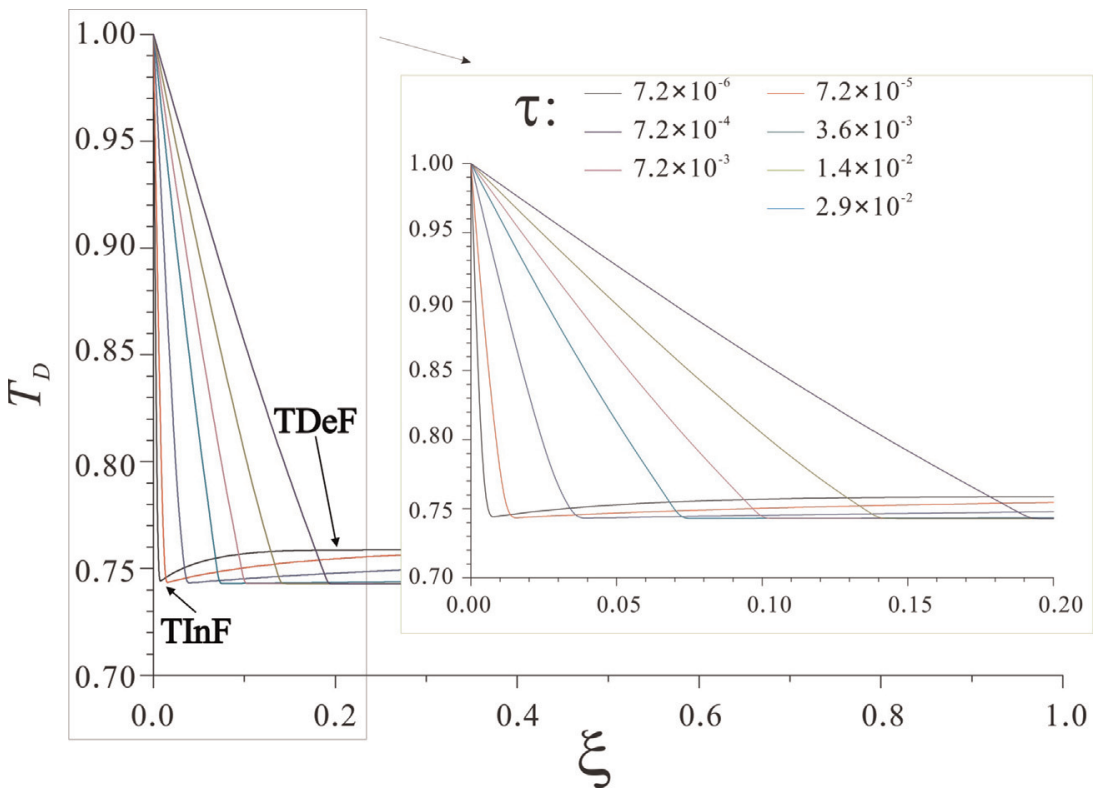

Fig. 3. Evolution of the temperature after depressurization and heating, the right side means "before". 


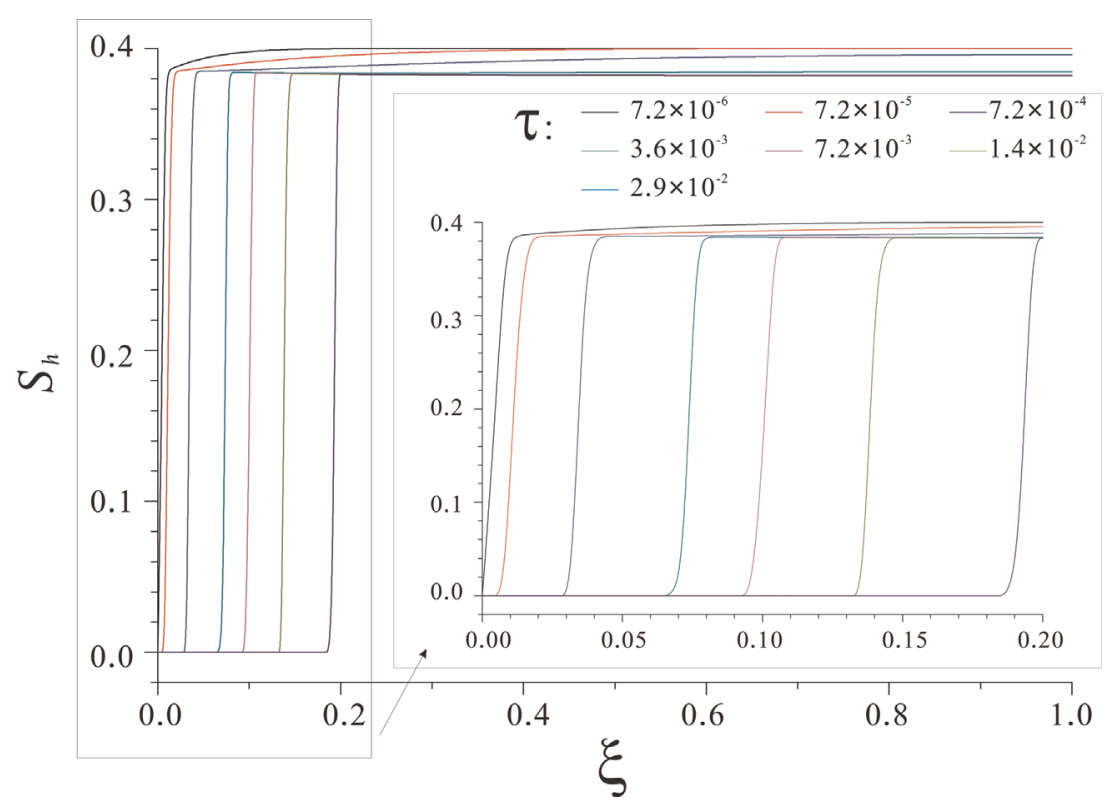

Fig. 4. Evolution of the hydrate saturation after depressurization and heating, the right side means "before".

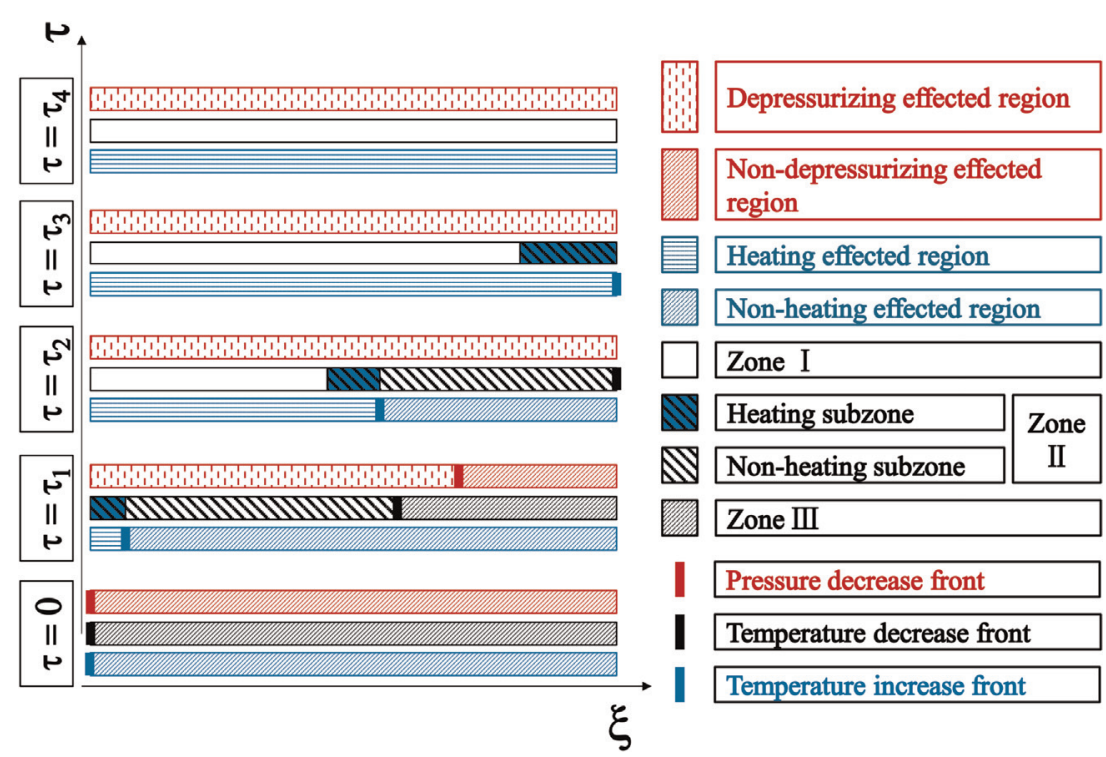

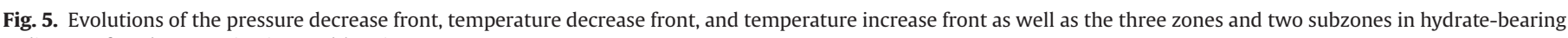
sediment after depressurization and heating.

to $x_{T I n}$;

Stage II $\left(\tau_{1} \sim \tau_{3}\right): x_{\text {sub }}$ is calculated by subtracting $x_{\mathrm{I}}$ from $x_{T I n}$;

Stage III $\left(\tau_{3} \sim \tau_{4}\right): x_{\text {sub }}$ is estimated by deducting $x_{\text {I }}$ out of $L$.

Therefore, the thicknesses of Zone II and the heating subzone can be calculated based on the locations of PDe, TDeF, and TInF as well as the thickness of Zone I, as discussed in the following section.

\subsection{Solutions analysis}

The evolution of the thickness of Zone I depends on the changes of the GH dissociation time and the start time at any location. The latter one is controlled by the propagation of TDeF.

Based on Eqs. (22), (23), (24), and (25), we can express $P_{D}, T_{D}$, and $S_{h}$ as follows:

$$
\left[\begin{array}{c}
P_{D} \\
T_{D} \\
S_{h}
\end{array}\right]=\left[\begin{array}{c}
f_{P}\left(\frac{t}{t^{*}}, \frac{x}{x^{*}}, \mathrm{M}_{\Pi}, \mathrm{M}_{D}\right) \\
f_{T}\left(\frac{t}{t^{*}}, \frac{x}{x^{*}}, \mathrm{M}_{\Pi}, \mathrm{M}_{D}\right) \\
f_{S H}\left(\frac{t}{t^{*}}, \frac{x}{x^{*}}, \mathrm{M}_{\Pi}, \mathrm{M}_{D}\right)
\end{array}\right]
$$

where $M_{\Pi}$ and $M_{D}$ are expressed as follows:

$$
M_{\Pi}=\left[\Pi_{i=1,2,3,4}\right]
$$

$M_{D}=\left[\Theta_{i=g, w, h}, \quad \Gamma_{i=1,2,3,4,5,6,7}\right]$

Based on Eq. (31), $x_{P D e}, x_{T D e}, x_{T I n}$ and the hydrate dissociation time at any location $\left(\Delta t_{S H}\right)$ can be written by the following equation: 

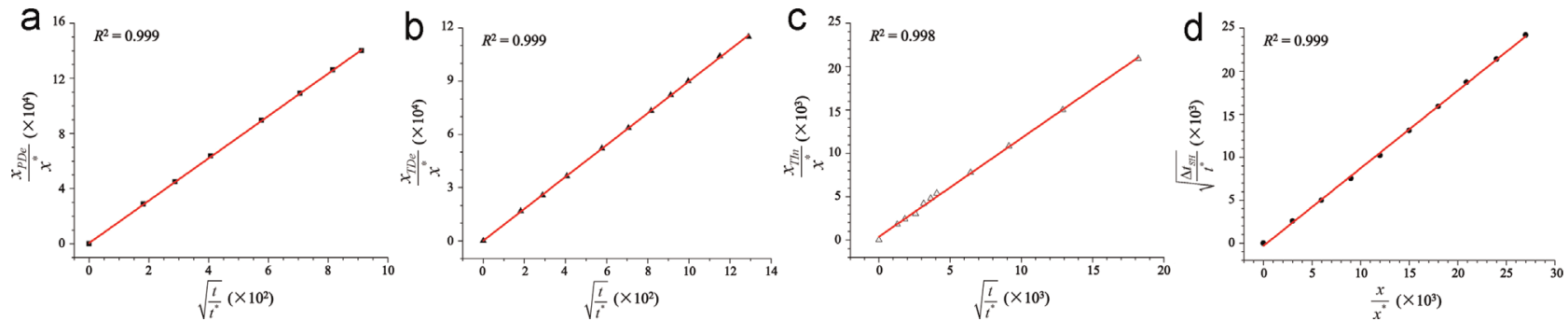

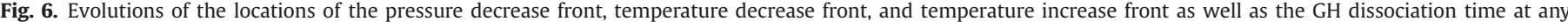
location, the red lines stand for the fitting lines and the black dots stead for the numerical simulation data.

$\left[\begin{array}{c}\frac{x_{P D e}}{x^{*}} \\ \frac{x_{T D e}}{x^{*}} \\ \frac{x_{T I n}}{x^{*}} \\ \frac{\Delta t_{S H}}{t^{*}}\end{array}\right]=\left[\begin{array}{l}F_{P D e}\left(\frac{t}{t^{*}}, \mathrm{M}_{\Pi}, \mathrm{M}_{D}\right) \\ F_{T D e}\left(\frac{t}{t^{*}}, \mathrm{M}_{\Pi}, \mathrm{M}_{D}\right) \\ F_{T I n}\left(\frac{t}{t^{*}}, \mathrm{M}_{\Pi}, \mathrm{M}_{D}\right) \\ F_{S H}\left(\frac{x}{x^{*}}, \mathrm{M}_{\Pi}, \mathrm{M}_{D}\right)\end{array}\right]$

Evolutions of $x_{P D e}, x_{T D e}, x_{T I n}$ and $\Delta t_{S H}$ which are calculated by the numerical simulation code as well as the fitting lines are shown in Fig. 6a-d. Fig. 6a-c shows that $\frac{x_{P D e}}{x^{*}}, \frac{x_{\text {TDe }}}{x^{*}}$, and $\frac{x_{T l n}}{x^{*}}$ are all linear with $\sqrt{\frac{t}{t^{*}}}$. In addition, Fig. $6 \mathrm{~d}$ shows that $\sqrt{\frac{\Delta t_{S H}}{t^{*}}}$ is linear with $\sqrt{\frac{x}{x^{*}}}$. These four linear relationships described above can be presented as follows:

$\left[\begin{array}{c}\frac{x_{P D e}}{x^{*}} \\ \frac{x_{T D e}}{x^{*}} \\ \frac{x_{T I n}}{x^{*}}\end{array}\right]=\left[\begin{array}{c}\Psi_{P D e}\left(M_{\Pi}, M_{D}\right) \\ \Psi_{T D e}\left(M_{\Pi}, M_{D}\right) \\ \Psi_{T I n}\left(M_{\Pi}, M_{D}\right)\end{array}\right] \sqrt{\frac{t}{t^{*}}}$

$\sqrt{\frac{\Delta t_{S H}}{t^{*}}}=\Psi_{S H}\left(M_{\Pi}, M_{D}\right) \frac{x}{x^{*}}$

where the coefficients $\Psi_{P D e}, \Psi_{T D e}, \Psi_{T I n}$, and $\Psi_{S H}$ are constants because dimensionless parameters in $M_{\Pi}$ and $M_{D}$ change little or are constant. The coefficients can be determined by the linear fit of the numerical simulation data.

According to Eqs. (35) and (36), $x_{\mathrm{I}}$ can be calculated by the following equation:

$\frac{x_{\mathrm{I}}}{x^{*}}=\frac{\Psi_{\mathrm{TDe}}}{\sqrt{1+\left(\Psi_{T D e} \Psi_{S H}\right)^{2}}} \sqrt{\frac{t}{t^{*}}}$

Thus, $x_{\text {II }}$ can be estimated as follows:

Stage I:

$\frac{x_{\mathrm{II}}}{x^{*}}=\frac{x_{T D e}}{x^{*}}=\Psi_{T D e} \sqrt{\frac{t}{t^{*}}}$

Stage II:

$\frac{x_{\mathrm{II}}}{x^{*}}=\frac{\sqrt{1+\left(\Psi_{\mathrm{TDe}} \Psi_{S H}\right)^{2}}-1}{\sqrt{1+\left(\Psi_{T D e} \Psi_{S H}\right)^{2}}} \Psi_{T D e} \sqrt{\frac{t}{t^{*}}}$

Stage III:

$\frac{x_{\text {II }}}{x^{*}}=\frac{L}{x^{*}}-\frac{x_{I}}{x^{*}}$

Similarly, $x_{\text {sub }}$ can be evaluated by the following equations: Stage I: $\frac{x_{\text {sub }}}{x^{*}}=\frac{x_{T I n}}{x^{*}}=\Psi_{T I n} \sqrt{\frac{t}{t^{*}}}$

Stage II:

$\frac{x_{\text {sub }}}{x^{*}}=\left[\Psi_{T I n}-\frac{\Psi_{\text {TDe }}}{\sqrt{1+\left(\Psi_{\text {TDe }} \Psi_{S H}\right)^{2}}}\right] \sqrt{\frac{t}{t^{*}}}$

Stage III:

$\frac{x_{\text {sub }}}{x^{*}}=\frac{L}{x^{*}}-\frac{x_{I}}{x^{*}}$

Obviously, $\Psi_{T D e}, \Psi_{T I n}$, and $\Psi_{S H}$ are of significant importance in determining the spatial distribution of GH dissociation. Effects of the dimensionless parameters closely related to these three coefficients are discussed in the following section.

\section{Effects of the dimensionless parameters}

This section presents calculations of the magnitudes of the dimensionless parameters in $M_{\Pi}$ and $M_{D}$ based on the reported insitu tests. Then, the key dimensionless parameters affecting the spatial distribution of GH dissociation are discussed.

The reported in-situ tests of gas production from GH are carried out in Mackenzie Delta, Alaska North Slope, and Nankai Trough (Takahashi et al., 2003; Hancock et al., 2005; Kurihara et al., 2008; Moridis et al., 2011; ConocoPhillips, 2012; David, 2013). During these in-situ production tests, downhole pressures of the production wells in Mallik, Ignik Sikumi, and Nankai Trough are reduced from 11.2 MPa to 7.3 MPa (Kurihara et al., 2008; Moridis et al., 2011), 8.1-1.8 MPa (ConocoPhillips, 2012), and 13.5-4.5 MPa (David, 2013) respectively. Besides, the downhole temperature of Mallik 5L-38 well maintains at about $343 \mathrm{~K}$ (Takahashi et al., 2003; Hancock et al., 2005) to induce the GH dissociation. The in-situ data show that the magnitudes of the pressures and the temperature in the production wells normally stay at $(1.8-7.3) \times 10^{6} \mathrm{~Pa}$ and $3.4 \times 10^{2} \mathrm{~K}$ respectively. In addition, the magnitudes of the density, the specific heat and the thermal conductivity of HBS naturally stayed at $(0.9-2.6) \times 10^{3} \mathrm{~kg} / \mathrm{m}^{3},(0.8-4.2) \times 10^{3} \mathrm{~J} / \mathrm{kg} / \mathrm{K}$ and $(1.0-4.0) \times 10^{0} \mathrm{~W} / \mathrm{m} / \mathrm{K}$ respectively (Sun et al., 2005; Waite et al., 2009). Besides, the parameters in the absolute and relative permeability models and the model of intrinsic kinetic of $\mathrm{GH}$ dissociation are constant (Table 2). Therefore, the dimensionless parameters in $M_{D}$ change little in reality.

Defining $t_{h c}$ as $t_{0}$, the dimensionless parameters in $M_{\Pi}$ are calculated using the parameters in Tables 1 and 2. The parameter $\Pi_{4}$ decreases with a higher temperature and a lower pressure in the production well. The magnitude of the minimal $\Pi_{4}$ is still $10^{5}$ based on the parameters in the in-situ tests, which indicates that the intrinsic kinetic $\mathrm{GH}$ dissociation is much faster than the conductive heat transfer. Thus, $\Pi_{4}$ has little effect on the three coefficients, $\Psi_{\text {TDe }}, \Psi_{T I n}$, and $\Psi_{S H}$. Because the absolute permeability of 
HBS can vary from Darcy to Millidarcy (Sun et al., 2005; Waite et al., 2009; Dai et al., 2011) in nature, $\Pi_{2}$ can change in several orders around one, causing the gas flow becomes from faster to slower than the conductive heat transfer. Unlike $\Pi_{2}, \Pi_{3}$ naturally exceeds one, a fact that indicates that the water flow is usually slower than the conductive heat transfer.

To summarize, $\Pi_{2}$ is the key dimensionless parameter on the spatial distribution of GH dissociation in the clay-silty sediments, and its sensitivity is discussed in the following section.

\section{Sensitivity of $\Pi_{2}$}

Since thermal properties of HBS are changeless in the order of magnitude, $\Pi_{2}$ is varied by changing the absolute permeability of HBS. The sensitivity analysis considers three conditions with different absolute permeabilities (respectively $1.0 \mathrm{mD}, 0.1 \mathrm{mD}$, and $0.01 \mathrm{mD}$ ). Four coefficients under these three conditions are summarized in Table 3.

Fig. 7A-C shows the lengths of Zone II under the absolute permeability of $1.0 \mathrm{mD}, 0.1 \mathrm{mD}$, and $0.01 \mathrm{mD}$, respectively. The lengths reach maximums $4.9 \mathrm{~m}$ at $t=6.3 \times 10^{3} \mathrm{~s}, 4.8 \mathrm{~m}$ at $t=6.3 \times 10^{4} \mathrm{~s}$ and $4.4 \mathrm{~m}$ at $t=6.3 \times 10^{5} \mathrm{~s}$, respectively, then decrease to zero sequentially. The lengths of Zone I under different absolute permeabilities all approach $5.0 \mathrm{~m}$ at $t=4.0 \times 10^{7} \mathrm{~s}$. It then follows that (i) as $\Pi_{2}$ decreases, the time for Zone II to reach its maximal length increases, but the time for Zone I arriving at $5.0 \mathrm{~m}$ does not change; (ii) the maximal length of Zone II is shorter for a lower $\Pi_{2}$.

Shown in Fig. 8, the maximum lengths of the heating subzone under different absolute permeabilities of $1.0 \mathrm{mD}, 0.1 \mathrm{mD}$, and $0.01 \mathrm{mD}$ are $0.14 \mathrm{~m}, 0.06 \mathrm{~m}$, and $0.02 \mathrm{~m}$, respectively. With $\Pi_{2}$ decreasing, the maximal length of the heating subzone decreases. Interestingly, times for the length of the heating subzone to reach the maximums under different cases are all $3.8 \times 10^{7} \mathrm{~s}$, and times for the length of Zone I to expand to $5.0 \mathrm{~m}$ are all $4.0 \times 10^{7} \mathrm{~s}$. The maximal lengths of the heating subzone are in the range of $2.9 \%$, $1.3 \%$, and $0.5 \%$ of the maximal lengths of Zone II respectively. Therefore, the heating subzone can be treated as a discontinuous interface, but the dissociating zone cannot be treated as a discontinuous interface after depressurization and heating.

\section{Discussion}

The numerical simulation code mentioned in Section 4.2 is verified by a laboratory-scale experiment of hydrate dissociation by depressurization in a Berea sandstone core carried out by Masuda et al. (1999). It is noteworthy that the whole chamber containing the sandstone core is emerged in an air bath to maintain a constant temperature, which indicates that the heat for hydrate dissociation can be transferred through the two ends and the cylindrical side area of the sandstone core. Past work by Masuda et al. (1999) suggested a convective heat transfer through the cylindrical side area. Therefore, a part simulating the heat transfer through the cylindrical side area is added in the right side of the

Table 3

Four coefficients under three conditions with different absolute permeabilities (respectively $1.0 \mathrm{mD}, 0.1 \mathrm{mD}$, and $0.01 \mathrm{mD}$ ).

\begin{tabular}{lllllll}
\hline & $K_{0}(\mathrm{mD})$ & $\Pi_{2}$ & $\Psi_{P D e}$ & $\Psi_{\text {TDe }}$ & $\Psi_{\text {TIn }}$ & $\Psi_{S H}$ \\
\hline MH1 & 1.0 & $1.8 \times 10^{1}$ & 153 & 89.8 & 1.14 & 0.902 \\
MH2 & 0.10 & 1.8 & 48.5 & 28.6 & 1.12 & 0.901 \\
MH3 & 0.01 & $1.8 \times 10^{-1}$ & 15.4 & 9.60 & 1.11 & 0.899 \\
\hline
\end{tabular}

energy conservation Eq. (18a)-(18d), and the new energy conservation equation is shown in Eq. (40). In addition, the temperatures in the two ends of the sandstone core are constant, and the boundary condition in the right side needs to be revised as Eq. (41). Conditions of the experiment are summarized in Table 4. Although the initial hydrate saturation is suggested to be 0.433 by Masuda et al. (1999), another hydrate saturation of 0.497 calculated by the cumulative produced gas volume of 9.1 Standard Liters is adopted in this work.

$\alpha \frac{\partial T}{\partial t}+\beta \frac{\partial T}{\partial x}-\frac{\partial}{\partial x}\left(\lambda \frac{\partial T}{\partial x}\right)$

$=\dot{m}_{h} \Delta H+\frac{4}{D} h\left(T_{b}-T\right)$

$\frac{\partial P_{g}}{\partial x}=0$
$T=T_{b}$ at $x=L$

The cumulative produced gas volume is simulated by the numerical simulation code. Fig. 9 demonstrates that the simulated gas production volume largely matches the experimental data. The slight mismatch, less than $4.4 \%$ of the maximal cumulative gas production, can be attributed to the lack of real experimental data. Such data include the heat convective coefficient $h$ which is of significance on the behavior of hydrate dissociation. Therefore, the numerical simulation code is credible for solving the locations of the fronts and the dissociation time at any location.

Two assumptions in this work are different from the in-situ tests. First, we assume that HBS is adiabatic with an over-layer and a base-layer, although the over-layer and the base-layer can provide heat for $\mathrm{GH}$ dissociation in in-situ conditions. In this work, the temperature in the non-heating subzone decreases and approaches the equilibrium temperature corresponding to $P_{\text {well }}$ because the heat for hydrate dissociation is only supplied by the sensible heat of HBS, and hydrate stops dissociating at the saturation of 0.38 . In nature, the heat for GH dissociation in the nonheating subzone is provided not only by the sensible heat of HBS, but also by the heat transfer from the over-layer and the baselayer to HBS. Therefore, the hydrate saturation at which hydrate stops dissociating in the non-heating subzone in nature is lower than that in this work, which leads to an deviation of our model. However, the thermal conductivity of the clay-silty sediments in Shenhu area of South China Sea is very low, and the level of deviation caused by this assumption is acceptable. In permafrost sediments which have relatively large thermal conductivities, the level of deviation is acceptable only in the early stage of hydrate dissociation process because the heat exchange rate at latter stage becomes too high that it cannot be ignored. Another 2D model needs to be developed to quantitatively estimate the effect of the heat transfer from the over-layer and the base-layer on the spatial distribution of hydrate dissociation in sediments. This, however, is beyond the scope of this work.

Secondly, we assume that the 1D HBS is finite in the length which is necessary to the numerical simulation code, while HBS is long enough to be effectively treated as a semi-infinite sediment. PDeF, TDeF, TInF, and HCoF infinitely propagate from the production well into HBS. Therefore, the lengths of the dissociating zone and the heating subzone can never reach their maximums, which further causes the absence of the third evolution stages of the dissociating zone and the heating subzone. And the absence indicates that the third evolution stages of the dissociating zone and the heating subzone are not existed in nature. Since the HBS can be treated as semi-infinite sediments before TDeF reaches the edge of HBS, this assumption has no influence on the applications of the first and the second evolution stages of the dissociating zone and 

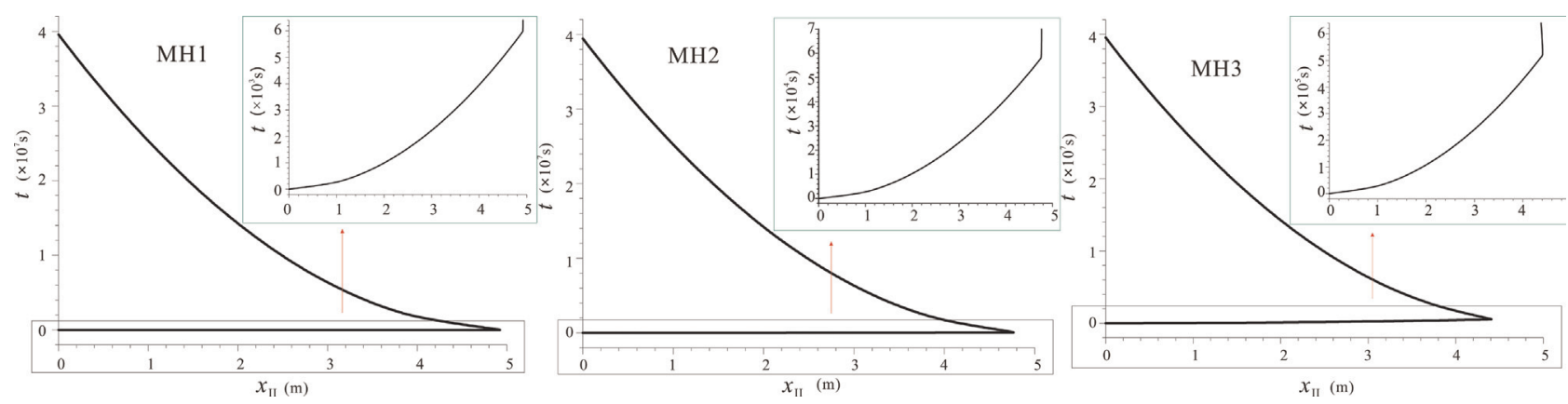

Fig. 7. Evolutions of lengths of Zone II after depressurization and heating.

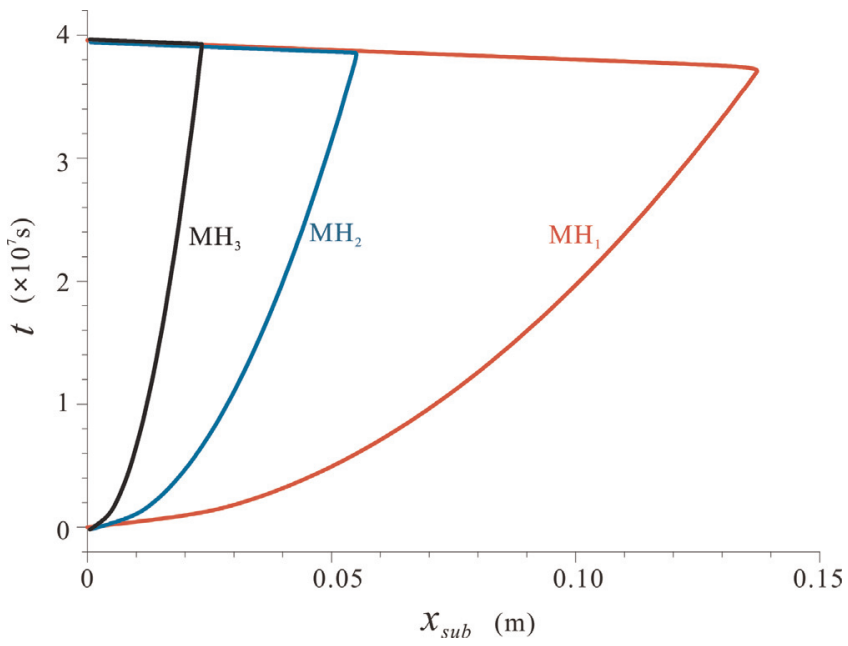

Fig. 8. Evolutions of length of the heating subzone after depressurization and heating.

Table 4

Conditions of laboratory-scale experiment of hydrate dissociation by depressurization (Masuda et al., 1999; Liang et al., 2010)

\begin{tabular}{ll}
\hline Parameter & Value \\
\hline$S_{h 0}$ & 0.497 \\
$S_{w 0}$ & 0.206 \\
$S_{g 0}$ & 0.297 \\
$T_{0}(\mathrm{~K})$ & 275.45 \\
$P_{g 0}(\mathrm{MPa})$ & 3.75 \\
$P_{w e l l}(\mathrm{MPa})$ & 2.84 \\
$T_{b}(\mathrm{~K})$ & 275.45 \\
$\phi$ & 0.182 \\
$K_{0}(\mathrm{mD})$ & 98.0 \\
$D(\mathrm{~cm})$ & 5.1 \\
$L(\mathrm{~cm})$ & 30 \\
$h\left(\mathrm{~W} / \mathrm{m}^{2} / \mathrm{K}\right)$ & 16.6 \\
\hline
\end{tabular}

the heating subzone in the real world.

A number of experimental and numerical studies have shown that the gas production rate reaches a relatively high level in the early stage of the gas recovery by depressurization, but decreases dramatically in the latter stage (Moridis, 2003; Moridis and Reagan, 2007; Bai et al., 2009; Collett et al., 2011). Moreover, all the in-situ gas production tests showed that the long-term recovery of hydrate by depressurization is of poor efficiency, which limits the commercial exploitation of GH. The model in this work can perfectly explain these two phenomena. The dissociating zone expands quickly, producing a large amount of sensible heat available

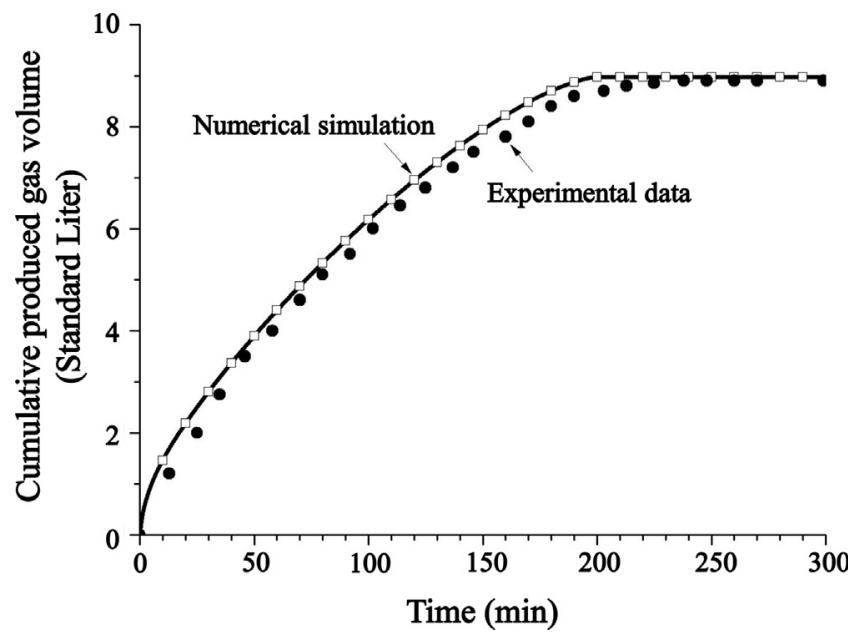

Fig. 9. Cumulative gas production comparison between experimental data and the simulated result.

for GH dissociation in a relatively short time. Thus, a great deal of GH can dissociate in the early stage of gas production process, leading to a higher gas production rate in this period. However, the rate of GH dissociation in the non-heating subzone decreases obviously which even falls to zero because sensible heat stops being available and conductive heat transfer from the over-layer and the base-layer becomes very slow. Furthermore, since the heat conduction from the production well is of low velocity too, the gas production rate in the latter stage is relatively low. In a word, gas production at the beginning is controlled by gas flow and has a high rate, while at the latter stage it is controlled by the conductive heat transfer and falls in rate.

Most of GH is dissociated in the heating subzone with enough heat supplied from the production well in this work. Although the hydrate saturation at which the hydrate stops dissociating becomes low in nature, there is still a majority of GH dissociating with energy supplied by conductive heat transfer from the production well and the over-layer and the base-layer. Therefore, the conductive heat transfer is the dominant factor of gas production efficiency. As a result of that, current methods (depressurization, heat injection, etc.), as long as the conductive heat transfer is low, are undoubtedly with low efficiency.

This work has achieved a simple solution for the spatial distribution of GH dissociation, allowing an accomplishment of the hydrate dissociation front forecast which is vital for the plan design of gas recovery and potential hazards analysis; it also finds that low efficiency of heat conduction from the environment is the dominant factor for enhancing gas production efficiency in the clay-silty sediments. New method with high efficiency of heat transfer is of substantial importance in commercial recovery of GH. 


\section{Conclusions}

A 1D model incorporating conductive and convective heat transfer, two-phase fluid flow, and intrinsic kinetics of hydrate dissociation is presented to predict the spatial distribution of $\mathrm{GH}$ dissociation in clay-silty sediments.

The proposed solutions are simple with the coefficients easily to evaluate. Three zones occur naturally in HBS, namely, a dissociated zone, a dissociating zone, and an undissociated zone. The dissociating zone is further classified into a heating subzone and a non-heating subzone. Without assuming the discontinuous interface and the sudden decrease of pressure, the hydrate dissociation front, and the lengths of the dissociating zone and the heating subzone are investigated. After discussing the effects of the absolute permeability of sediment on the spatial distribution of $\mathrm{GH}$ dissociation, we arrive at the following conclusions:

1. The expansion velocity of the dissociating zone (equals the velocity of the hydrate dissociation front) is about 90 times faster than that of the heating subzone (equals the velocity of the heat conduction front) in the clay-silty sediments with the absolute permeability of $1 \mathrm{mD}$ and the hydrate saturation of 0.4. Besides, a higher absolute permeability causes a faster expansion velocity of the dissociating zone, but barely affects the expansion velocity of the heating subzone.

2. The thicknesses of the dissociating zone and the heating subzone as well as the propagation distance of the hydrate dissociation front are all linear with the square root of time in nature. In addition, the square root of hydrate dissociation time at any location is also linear with the distance between the location and the production well.

3. In the clay-silty sediments, the thickness of the heating subzone is less than $5 \%$ of the thickness of the dissociating zone in the latter stage of the hydrate dissociation process, which indicates that the dissociating zone cannot be treated as a discontinuous interface, but the heating subzone can be simplified as a discontinuous interface with impunity.

\section{Acknowledgment}

We thank Zheng Zhemin and Tan Qingming for technical assistance. Funding of this work has been provided by the National Natural Science Foundation of China (Nos. 11402131, 11272314, and 41376078). Their support is gratefully acknowledged.

\section{Appendix A. Derivation of dimensionless controlling equations}

Substituting Eqs. (6)-(10) into Eq. (5), we get

$\dot{m}_{h}=-k_{0}\left(N_{H} M_{w}+M_{g}\right) \sqrt{\frac{\phi^{3}}{2 K_{0}}} f_{\text {hydrate }}$

where

$f_{\text {hydrate }}=e^{-\frac{\Delta E}{R T}}\left(1-S_{h}\right)^{\frac{3-N}{2}}\left(a e^{b-\frac{c}{T}}-P_{g}\right)$

Substituting Eqs. (3), (10), (11), (14), and (A.1) into Eq. (1), we get

$$
\begin{aligned}
& \frac{\partial}{\partial t}\left(\frac{P_{g}}{T} S_{g}\right)-\frac{\partial}{\partial x}\left[\frac{k_{r g} K_{0}}{\mu_{g} \phi}\left(1-S_{h}\right)^{N} \frac{P_{g}}{T} \frac{\partial P_{g}}{\partial x}\right] \\
& =\frac{k_{0} R}{\phi} \sqrt{\frac{\phi^{3}}{2 K_{0}}} f_{\text {hydrate }}
\end{aligned}
$$

Substituting Eqs. (3), (4), (10), (11), and (A.1) into Eq. (2) for water, then ignoring partial derivative of the capillary pressure, we get

$\frac{\partial S_{w}}{\partial t}-\frac{\partial}{\partial x}\left[\frac{k_{r w} K_{0}}{\mu_{w} \phi}\left(1-S_{h}\right)^{N} \frac{\partial P_{g}}{\partial x}\right]$

$=\frac{k_{0} N_{H} M_{w}}{\phi \rho_{w}} \sqrt{\frac{\phi^{3}}{2 K_{0}}} f_{\text {hydrate }}$

Substituting (Eqs. (A.1a) and A.1b) into Eq. (2), we get

$\frac{\partial S_{h}}{\partial t}=-\frac{k_{0}\left(N_{H} M_{w}+M_{g}\right)}{\phi \rho_{h}} \sqrt{\frac{\phi^{3}}{2 K_{0}}} f_{\text {hydrate }}$

Substituting Eqs. (11), (14), and (A.1) into Eqs. (18a)-(18d), we get

$\alpha \frac{\partial T}{\partial t}-\beta \frac{\partial T}{\partial x}-\frac{\partial}{\partial x}\left(\lambda \frac{\partial T}{\partial x}\right)$

$=-k_{0}\left(N_{H} M_{w}+M_{g}\right) \sqrt{\frac{\phi^{3}}{2 K_{0}}} \Delta H f_{\text {hydrate }}$

where

$\begin{aligned} \alpha= & \frac{\phi S_{g} P_{g} M_{g} C_{g}}{R T}+(1-\phi) \rho_{s} C_{s} \\ & +\sum_{i=w, h} \phi S_{i} \rho_{i} C_{i}\end{aligned}$

$\beta=\left(\frac{P_{g} M_{g} C_{g} k_{r g}}{R T \mu_{g}}+\frac{\rho_{w} C_{w} k_{r w}}{\mu_{w}}\right) K \frac{\partial P_{g}}{\partial x}$

Then, dimensionless forms of Eqs. (A.2), (A.3), (A.4), and (A.5ac) are shown in Eqs. (22), (23), (24), and (25), respectively. Dimensionless variables and parameters are given as follows:

$P_{D}=\frac{P_{g}}{P_{\text {well }}}$

$T_{D}=\frac{T}{T_{\text {heat }}}$

$\tau=\frac{t}{t_{0}}$

$\xi=\frac{x}{x_{0}}$

$a_{1}=\frac{\left(k_{r g}\right)_{D}\left(1-S_{h}\right)^{N}}{\left(1-S_{h 0}\right)^{N} \phi}$

$a_{2}=\frac{\Gamma_{5} \Gamma_{6}\left(e^{-I_{1}}\right)^{\frac{1-T_{D}}{T_{D}}}\left(1-S_{h}\right)^{\frac{3-N}{2}}}{\left(1-S_{h 0}\right)^{\frac{3-N}{2}} \phi}$

$a_{3}=\Gamma_{2}\left(e^{-\Gamma_{3}}\right)^{\frac{1-T_{D}}{T_{D}}}$ 
$b_{1}=\frac{\left(k_{r w}\right)_{D}\left(1-S_{h}\right)^{N}}{\left(1-S_{h 0}\right)^{N} \phi}$

(A.11a)

$b_{2}=\frac{\left(1-\Gamma_{6}\right) \Gamma_{7}\left(e^{-T_{1}}\right)^{\frac{1-T_{D}}{T_{D}}}\left(1-S_{h}\right)^{\frac{3-N}{2}}}{\left(1-S_{h 0}\right)^{\frac{3-N}{2}} \phi}$

(A.11b)

$c_{1}=\frac{\left(e^{-T_{1}}\right)^{\frac{1-T_{D}}{T_{D}}}\left(1-S_{h}\right)^{\frac{3-N}{2}}}{\left(1-S_{h 0}\right)^{\frac{3-N}{2}} \phi}$

$d_{1}=\frac{\alpha}{\alpha_{0}}$

(A.12)

(A.13a)

$d_{2}=\frac{\Theta_{g}\left(k_{r g}\right)_{D}\left(1-S_{h}\right)^{N}}{\left(1-S_{h 0}\right)^{N}}$

(A.13b)

$d_{3}=\frac{\Theta_{w}\left(k_{r w}\right)_{D}\left(1-S_{h}\right)^{N}}{\left(1-S_{h 0}\right)^{N}}$

(A.13c)

$d_{4}=\frac{\Theta_{h}\left(e^{-I_{1}}\right)^{\frac{1-T_{D}}{T_{D}}}\left(1-S_{h}\right)^{\frac{3-N}{2}}}{\left(1-S_{h 0}\right)^{\frac{3-N}{2}}}$

(A.13d)

$\lambda_{D}=\frac{\lambda}{\lambda_{0}}$

(A.14)

$\Gamma_{4}=\frac{H_{0}}{C_{0} T_{\text {heat }}}$

where

$\left(k_{r g}\right)_{D}=\frac{k_{r g}}{k_{r g} 0}$

(A.16a)

$\left(k_{r w}\right)_{D}=\frac{k_{r w}}{k_{r w 0}}$

(A.16b)

$k_{r g 0}=\left(\frac{\frac{S_{g 0}}{S_{w 0}+S_{g 0}}-S_{g r}}{1-S_{w r}-S_{g r}}\right)^{n_{g}}$

(A.17a)

$k_{r w 0}=\left(\frac{\frac{S_{w 0}}{S_{w 0}+S_{g 0}}-S_{w r}}{1-S_{w r}-S_{g r}}\right)^{n_{w}}$

(A.18b)

$\alpha_{0}=\phi S_{g 0} \frac{P_{\text {well }} M_{g}}{T_{\text {heat }} R} C_{g}+(1-\phi) \rho_{s} C_{s}+\sum_{i=w, h} \phi S_{i 0} \rho_{i} C_{i}$

$\lambda_{0}=\sum_{i=g, w, h} \phi S_{i 0} \lambda_{i}+(1-\phi) \lambda_{s}$

$\Theta_{g}=\frac{\frac{P_{\text {well }} M_{g}}{T_{\text {heat }} C_{g}}}{\alpha_{0}}$

$\Theta_{w}=\frac{\rho_{w} C_{w}}{\alpha_{0}}$
$\Theta_{h}=\frac{-\rho_{h} C_{0}}{\alpha_{0}}$

$$
\Gamma_{1}=\frac{\Delta E}{T_{\text {heat }} R}
$$

$\Gamma_{2}=\frac{a \exp \left(b-\frac{c}{T_{\text {heat }}}\right)}{P_{\text {well }}}$

$\Gamma_{3}=\frac{c}{T_{\text {heat }}}$

$\Gamma_{5}=\frac{M_{g}}{N_{H} M_{w}+M_{g}}$

$\Gamma_{6}=\frac{\rho_{h}}{\frac{P_{\text {well }} M_{g}}{T_{\text {heat }} R^{R}}}$

$\Gamma_{7}=\frac{\rho_{h}}{\rho_{w}}$

$t_{h c}, t_{g s}, t_{w s}$, and $t^{*}$ in Eq. (26) are given as follows:

$t_{h c}=\frac{\alpha_{0} x_{0}^{2}}{\lambda_{0}}$

$t_{g s}=\frac{\mu_{g} x_{0}^{2}}{k_{r g 0} K_{0}\left(1-S_{h 0}\right)^{N} P_{\text {well }}}$

$t_{w s}=\frac{\mu_{w} x_{0}^{2}}{k_{r w 0} K_{0}\left(1-S_{h 0}\right)^{N} P_{w e l l}}$

$t^{*}=\frac{\rho_{h}}{k_{0}\left(N_{H} M_{w}+M_{g}\right) \sqrt{\frac{\phi^{3}}{2 K_{0}}}\left(1-S_{h 0}\right)^{\frac{3-N}{2}} P_{\text {well }} e^{I_{1}}}$

$x^{*}$ in Eq. (28) can be expressed as follows:

$x^{*}=\sqrt{\frac{\lambda_{0}}{\alpha_{0}} t^{*}}$

\section{References}

Amyx, J.W., Bass, D.M., Whiting, R.L., 1960. Petroleum Reservoir Engineering Physical Properties. McGraw-Hill, New York.

Anderson, B.I., Collett, T.S., Lewis, R.E., Dubourg, I., 2008. Using open hole and cased-hole resistivity logs to monitor gas hydrate dissociation during a therma test in the Mallik 5L-38 research well, Mackenzie Delta, Canada. Petrophysics 49 (3), 285-294.

Bai, Y.H., Li, QP. 2010. Simulation of gas production from hydrate reservoir by the combination of warm water flooding and depressurization. Sci. China Ser. E 53 (9), 2469-2476.

Bai, Y.H., Li, Q.P., Zhao, Y., Li, X.F., Du, Y., 2009. The experimental and numerical studies on gas production from hydrate reservoir by depressurization. Transp. Porous Med. 79 (3), 443-468.

Clarke, M., Bishnoi, P.R., 2001. Determination of the activation energy and intrinsic rate constant of methane gas hydrate decomposition. Can. J. Chem. Eng. 79 (1) 143-147.

Collett, T.S., Boswell, R., Lee, M.W., Anderson, B.J., Rose, K., Lewis, K.A., 2011. Evaluation of long-term gas hydrates production testing locations on the Alaska North Slope. Paper SPE 155504 Presented at the Arctic Technology Conference in Houston, 7-9 February, 2011.

ConocoPhillips, 2012. ConocoPhillips gas hydrate production test. Oil \& Natural Gas Technology. DOE Award No.: DE-NT0006553.

Dai, S., Lee, C., Santamarina, J.C., 2011. Formation history and physical properties of sediments from the Mount Elbert Gas Hydrate Stratigraphic Test Well, Alaska North Slope. Mar. Pet. Geol. 28 (2), 427-438.

David, C., 2013. Japanese test coaxes fire from ice. Nature 496, 409. 
Demirbas, A., 2010. Methane hydrates as potential energy resource: Part 2 - Methane production processes from gas hydrates. Energy Convers Manag. 51 (7), 1562-1571.

Gerami, S., Pooladi-Darvish, M., 2007. Predicting gas generation by depressurization of gas hydrates where the sharp-interface assumption is not valid. J. Pet Sci. Eng. 56 (1), 146-164.

Goel, N., Wiggins, M., Shah, S., 2001. Analytical modeling of gas recovery from in situ hydrates dissociation. J. Pet. Sci. Eng. 29 (2), 115-127.

Hancock, S.H., Collett, T.S., Dallimore, S.R., Satoh, T., Inoue, T., Huenhes, E., Henninges, J., Weatherill, B., 2005. Overview of thermal-stimulation productiontest results for the JAPEX/JNOC/GSC et al. Mallik 5L-38 gas hydrate production research well. Presented in Scientific Results from the Mallik 2002 Gas Hydrate Production Research Well Program, Mackenzie Delta, Northwest Territories, Canada. Geological Survey of Canada, Bulletin, vol. 585, p. 15.

Henninges, J., Huenges, E., Burkhardt, H., 2005. In situ thermal conductivity of gashydrate-bearing sediments of the Mallik 5L-38 well. J. Geophys. Res. 110 (B11). http://dx.doi.org/10.1029/2005JB003734.

Hong, H., Pooladi-Darvish, M., 2003. A numerical study on gas production from formations containing gas hydrates. Presented at the Canadian International Petroleum Conference in Calgary, Alberta, Canada, 10-12 June, 2003.

Hong, H., Pooladi-Darvish, M., 2005. Simulation of depressurization for gas production from gas hydrate reservoirs. J. Can. Pet. Technol. 44 (11), 39-46. http: //dx.doi.org/10.2118/05-11-03.

Ikegami, T., Morikami, Y., Fuji, K., Suzuki, K., Imasato, Y., Schlumberger, K.K., Chen, M.Y., Yasuda, M., 2008. Streaming potential measurement for hydrate dissociation monitoring. Presented at the 6th International Conference on Gas Hydrates in Vancouver, British Columbia, Canada, 6-10 July, 2008.

Ji, C., Ahmadi, G., Smith, D.H., 2001. Natural gas production from hydrate decomposition by depressurization. Chem. Eng. Sci. 56 (20), 5801-5814.

Kim, H.C., Bishnoi, P.R., Heidemann, R.A., Rizvi, S.S.H., 1987. Kinetics of methane hydrate decomposition. Chem. Eng. Sci. 42 (7), 1645-1653. http://dx.doi.org/ 10.1016/0009-2509(87)80169-0.

Klauda, J.B., Sandler, S.I., 2005. Global distribution of methane hydrates in ocean sediment. Energy Fuel 19 (2), 459-470. http://dx.doi.org/10.1021/ef049798o.

Kurihara, M., Funatsu, K., Ouchi, H., Masuda, Y., Yasuda, M., Yamamoto, K., Numasawa, M., Fujii, H., Dallimore, S.R., Wright, F., 2008. Analysis of the JOGMEC/ NRCan/Aurora Mallik gas hydrate production test through numerical simulation. Presented at the 6th International Conference on Gas Hydrates in Vancouver, British Columbia, Canada, 6-10 July, 2008.

Lee, S.Y., Holder, G.D., 2001. Methane hydrates potential as a future energy source. Fuel Process. Technol. 71, 181-186.

Li, G., Moridis, G.J., Zhang, K.N., Li, X.S., 2010. Evaluation of gas production potential from marine gas hydrate deposits in Shenhu area of South China Sea. Energy Fuel 24 (11), 6018-6033. http://dx.doi.org/10.1021/ef100930m.

Liang, H.F., Song, Y.C., Chen, Y., 2010. Numerical simulation for laboratory-scale methane hydrates dissociation by depressurization. Energy Convers. Manag. 51 (10), 1883-1890. http://dx.doi.org/10.1016/j.enconman.2010.02.018.

Liu, C.L., Ye, Y.G., Meng, O.G., He, X.L., Lu, H.L., Zhang, J., Liu, J., Yang, S.X., 2012. The characteristics of gas hydrates recovered from Shenhu Area in the South China Sea. Mar. Geol. 307-310, 22-27.

Masuda, Y., Naganawa, S., Ando, S., Sato, K., 1997. Numerical calculation of gas production performance from reservoirs containing natural gas hydrates. Paper 38291 Presented at the Annual Technical Conference. Society of Petroleum Engineers, San Antonio.

Masuda, Y., Fujinaga, Y., Naganawa, S., 1999. Modeling and experiment studies on dissociation of methane gas hydrate in Berea sandstone cores. Presented at the 3rd International Conference on Gas Hydrate in Salt Lake City, Utah, USA, 18-22 July, 1999.
Moridis, G.J., 2003. Numerical studies of gas production from methane hydrates. SPE J. 8 (4), 359-370 http://dx.doi.org/10.2118/87330-PA.

Moridis, G.J., Kowalsky, M., 2006. Depressurization-induced gas production from Class 1 and Class 2 hydrate deposits. Presented at TOUGH Symposium Conference in Berkeley, CA, USA, 15-17 May, 2006.

Moridis, G.J., Reagan, M.T., 2007. Strategies for gas production from oceanic Class 3 hydrate accumulations. Presented at the Offshore Technology Conference in Houston, Texas, USA, 30 April-3 May, 2007. 〈http://dx.doi.org/10.4043/18865MS).

Moridis, G.J., Reagan, M.T., Kim, S.J., Seal, Y., Zhang, K.N., 2009. Evaluation of the gas production potential of marine hydrate deposits in the Ulleung Basin of the Korean East Sea. SPE J. 14 (4), 759-781 http://dx.doi.org/10.2118/110859-PA.

Moridis, G.J., Collett, T.S., Pooladi-Darvish, M., Hancock, S.H., Santamarina, C., Boswell, R., Kneafsey, T.J., Rutqvist, J., Kowalsky, M.B., Reagan, M.T., Sloan, E.D., Sum, A., Koh, C., 2011. Challenges, uncertainties, and issues facing gas production from gas-hydrate deposits. SPE Reserv. Eval. Eng. 14 (1), 76-112 http:// dx.doi.org/10.2118/131792-PA.

Morikami, Y., Ikegami, T., Schlumberger, K.K., Chen, M.Y., Fujii, K., Yasuda, M., 2008. Electrical resistivity array measurement system development for gas hydrate dissociation monitoring. Presented at the 6th International Conference on Gas Hydrates in Vancouver, British Columbia, Canada, 6-10 July, 2008.

Primiero, P., Dreuillault, V., Sugiyama, H., Ikegami, T., Fujii, K., Fukuhara, M., Chang, C., Yasuda, M., 2008. Acoustic monitoring of methane hydrate production: system development, deployment and modeling/measurement evaluation. Presented at the 6th International Conference on Gas Hydrates in Vancouver, British Columbia, Canada, 6-10 July, 2008.

Selim, M.S., Sloan, E.D., 1989. Heat and mass transfer during the dissociation of hydrates in porous media. AIChE J. 35 (6), 1049-1052. http://dx.doi.org/ 10.1002/aic.690350620.

Sloan, E.D., Koh, C., 2007. Clathrate Hydrates of Natural Gases, third edition. CRC Press, USA.

Su, Z., He, Y., Wu, N.Y., Zhang, K.N., Moridis, G.J., 2012. Evaluation on gas production potential from laminar hydrate deposits in Shenhu Area of South China Sea through depressurization using vertical wells. J. Pet. Sci. Eng. 86-87, 87-98. http://dx.doi.org/10.1016/j.petrol.2012.03.008.

Sun, X., Nanchary, N., Mohanty, K.K., 2005. 1-D modeling of hydrate depressurization in porous media. Transp. Porous Med. 58 (3), 315-338. http://dx.doi.org/ 10.1007/s11242-004-1410-x.

Takahashi, H., Yonezawa, T., Fercho, E., 2003. Operation overview of the 2002 Mallik gas hydrate production research well program at the Mackenzie Delta in the Canadian Arctic. Presented at the Offshore Technology Conference in Houston, Texas, USA, 5-8 May, 2003.

Tan, Q.M., 2011. Dimensional Analysis: With Case Studies in Mechanics. Springer, Berlin Heidelberg.

Tsypkin, G.G., 2001. Regimes of dissociation of gas hydrates coexisting with a gas in natural strata. J. Eng. Phys. Thermophys. 74 (5), 1083-1089.

Waite, W.F., Santamarina, J.C., Cortes, D.D., Dugan, B., Espinoza, D.N., Germaine, J., Jang, J., Kneafsey, J.W., Shin, T.J., Soga, K., Winters, W.J., Yun, T.S., 2009. Physical properties of hydrate-bearing sediments. Rev. Geophys. 47 (4), RG4003.

Yang, H., Bai, Y.H., Li, Q.P., 2012. The simulation of gas production from oceanic gas hydrate reservoir by the combination of ocean surface warm water flooding with depressurization. Acta Mech. Sin. 28 (5), 1287-1295.

Yousif, M.H., Li, P.M., Selim, M.S., Sloan, E.D., 1990. Depressurization of natural gas hydrates in Berea sandstone cores. J. Incl. Phenom. Mol. Recognit. Chem. 8 (12), 71-88. http://dx.doi.org/10.1007/BF01131289. 